University of Nebraska - Lincoln

DigitalCommons@University of Nebraska - Lincoln

\title{
Transcript analysis and expression profiling of three heat shock protein 70 genes in the ectoparasitoid Habrobracon hebetor (Hymenoptera: Braconidae)
}

\author{
Hao-Liang Chen \\ Huazhong Agricultural University \\ Hong-Yu Zhang \\ Huazhong Agricultural University \\ James E. Throne \\ USDA-ARS, Manhattan, KS, james.throne@ars.usda.gov \\ Kun Yan Zhu \\ Kansas State University, kzhu@ksu.edu
}

Follow this and additional works at: https://digitalcommons.unl.edu/usdaarsfacpub

Chen, Hao-Liang; Zhang, Hong-Yu; Throne, James E.; and Zhu, Kun Yan, "Transcript analysis and expression profiling of three heat shock protein 70 genes in the ectoparasitoid Habrobracon hebetor (Hymenoptera: Braconidae)" (2014). Publications from USDA-ARS / UNL Faculty. 2006.

https://digitalcommons.unl.edu/usdaarsfacpub/2006

This Article is brought to you for free and open access by the U.S. Department of Agriculture: Agricultural Research Service, Lincoln, Nebraska at DigitalCommons@University of Nebraska - Lincoln. It has been accepted for inclusion in Publications from USDA-ARS / UNL Faculty by an authorized administrator of DigitalCommons@University of Nebraska - Lincoln. 


\title{
Transcript analysis and expression profiling of three heat shock protein 70 genes in the ectoparasitoid Habrobracon hebetor (Hymenoptera: Braconidae)
}

\author{
Hao-Liang Chen ${ }^{1,2,3,4}$, Hong-Yu Zhang ${ }^{1}$, James E. Throne ${ }^{3}$ and Kun Yan Zhu ${ }^{4}$ \\ ${ }^{1}$ State Key Laboratory of Agricultural Microbiology, Institute of Urban and Horticultural Pests, Hubei Insect Resources Utilization and \\ Sustainable Pest Management Key Laboratory, College of Plant Science and Technology, Huazhong Agricultural University, Wuhan, \\ ${ }^{2}$ Institute of Plant Protection and Agro-Products Safety, Anhui Academy of Agricultural Sciences, Hefei, China, ${ }^{3}$ USDA Agricultural \\ Research Service, Center for Grain \& Animal Health Research, Manhattan, KS, USA, and ${ }^{4}$ Department of Entomology, Kansas State \\ University, Manhattan, KS, USA
}

\begin{abstract}
Heat shock proteins (HSPs) are known as chaperones that help with folding of other proteins when cells are under environmental stresses. The upregulation of HSPs is essential for cold survival during insect diapause. The ectoparasitoid Habrobracon hebetor, a potential biological control agent, can enter reproductive diapause when reared at low temperature and short photoperiod. However, the expression of HSPs during diapause of $H$. hebetor has not been studied. In this study, we sequenced and characterized the full-length complementary DNAs of three Hsp70 genes (HhHsp70I, HhHsp70II and $H h H s p 70 I I I)$ from $H$. hebetor. Their deduced amino acid sequences showed more than $80 \%$ identities to their counterparts from other insect species. However, the multiple sequence alignment among the three deduced amino acid sequences of HhHsp70s showed only $46 \%$ identities. A phylogenetic analysis of the three HhHsp70s and all other known Hsp70 sequences from Hymenoptera clustered all the Hsp70s into four groups, and the three HhHsp70s were distributed into three different groups. Real-time quantitative polymerase chain reaction analysis showed that the expression of the three $H h H s p 70$ genes in $H$. hebetor reared at different conditions was quite different. HhHsp $70 I$ showed higher relative expression when $H$. hebetor were reared at $27.5^{\circ} \mathrm{C}$ than at two lower temperatures $\left(17.5^{\circ} \mathrm{C}\right.$ and $\left.20^{\circ} \mathrm{C}\right)$ regardless of the photoperiod, whereas HhHsp $70 I I$ showed higher expression when $H$. hebetor were reared at $20^{\circ} \mathrm{C}$ and $10: 14 \mathrm{~L}: \mathrm{D}$ than when reared at $17.5^{\circ} \mathrm{C}$ and either $16: 8 \mathrm{~L}: \mathrm{D}$ or $10: 14 \mathrm{~L}: \mathrm{D}$. In contrast, HhHSP70III was expressed at similar levels regardless of the rearing conditions. These results may suggest functional differences among the three HhHsp 70 genes in H. hebetor.
\end{abstract}

Key words ectoparasitoid, gene expression, Habrobracon hebetor, heat shock protein 70, phylogenetic analysis, quantitative RT-PCR

Correspondence: Hong-Yu Zhang, State Key Laboratory of Agricultural Microbiology, Institute of Urban and Horticultural Pests, Hubei Insect Resources Utilization and Sustainable Pest Management Key Laboratory, College of Plant Science and Technology, Huazhong Agricultural University, Wuhan 430070, Hubei, China. Tel: +86 278 7281156; fax: +86 2787396057 ; email: hongyu.zhang@mail.hzau.edu.cn. Kun Yan Zhu, Depart-

\section{Introduction}

The ectoparasitoid Habrobracon hebetor (Say) (= Bracon hebetor) (Hymenoptera: Braconidae) is considered as a potential biological control agent of several pyralid

ment of Entomology, Kansas State University, Manhattan, KS 66506, USA. Tel: 785532 4721; fax: 785532 6232; email: kzhu@ksu.edu 
moth pests infesting warehouses due to its rapid population growth (Amir-Maafi \& Chi, 2006; Balevski, 1984; Brower \& Press, 1990; Huang, 1986; Keever et al., 1986; Press et al., 1982). It has been used to suppress moth populations in stored products (Balevski, 1984; Brower \& Press, 1990; Cline \& Press, 1990; Garba \& Gaoh, 2008; Huang, 1986; Press et al., 1982) and in field crops (Cheng, 1991; Gerling, 1971; Imam et al., 2007; Uwais et al., 2006). Long-term storage of $H$. hebetor would facilitate its use in biological control programs, and we have recently shown that adult females appear to enter reproductive diapause when reared at $17.5^{\circ} \mathrm{C}$ or $20^{\circ} \mathrm{C}$ at $10: 14 \mathrm{~L}: \mathrm{D}$ (Chen et al., 2012) and that these females can be stored for up to 2 months without loss of vitality (Chen et al., 2013).

Diapause has been defined as a delay in development in response to regularly and recurring periods of adverse environmental conditions (Chapman, 1998; Tauber et al., 1986) and diapause can occur at different life stages in different insect species. Usually, tolerance to stresses, including heat, cold and desiccation, is greater in diapausing than in normal individuals (Tauber et al., 1986; Danks, 1987; Denlinger, 1991; Pullin, 1996; Goto et al., 1998; Foerster \& Doetzer, 2006; Denlinger, 2008). Much work has been done on the mechanisms of acquired stress tolerance, such as accumulation of polyols or sugars (Storey \& Storey, 1991), production of proteins to protect against freezing and desiccation (Kroeker \& Walker, 1991; Lee, 1991), and regulation of the unsaturation of fatty acyl chains in phospholipids (Wada et al., 1990).

Expression of heat shock proteins (HSPs) is another important adaptive strategy in stress tolerance (Yocum et al., 1998; Feder \& Hoffman, 1999; Rinehart et al., 2007; Zhang \& Denlinger, 2010; Aruda et al., 2011), and the upregulation of HSPs is essential for cold survival during insect diapause (Rinehart et al., 2007). For example, two heat shock protein $70(H s p 70)$ genes in the flesh fly, Sarcophaga crassipalpis, and one Hsp70 in the cotton bollworm, Helicoverpa armigera, were upregulated during pupal diapause (Rinehart et al., 2000; Rinehart et al., 2007; Bao \& Xu, 2011), and one Hsp70 was upregulated in adult diapause of the Colorado potato beetle, Leptinotarsa decemlineata (Yocum, 2001). In addition, Hsps were the only genes identified as essential to recovery from low-temperature damage (Michaud, 2007). Knowing which $H s p$ genes are upregulated or downregulated during diapause may allow enhancement of diapause and prolonging the duration of lowtemperature storage of insects by finding ways to artificially control the expression of these genes.

In an effort to better understand the diapause process in $H$. hebetor with the intent of lengthening the period that the females can be stored, in this study we investigated transcriptional response of three $H s p 70$ genes in females reared at conditions that appear to induce reproductive diapause. We first obtained partial complementary DNA (cDNA) sequences of $H s p 70$ by using degenerate primers, and then used $3^{\prime}$ and $5^{\prime}$ RACE (rapid amplification of cDNA ends). After we obtained the full-length cDNAs putatively encoding Hsp70s, we conducted reverse transcription quantitative PCR (RT-qPCR) to examine transcriptional responses of the three $H s p 70$ genes in adults of $H$. hebetor reared at different conditions.

\section{Materials and methods}

\section{Insects}

A field strain of $H$. hebetor was collected in Parlier, CA, USA, in October 2009, and the colony was maintained in the laboratory on last instar larvae of the Indian meal moth, Plodia interpunctella (Hübner), at $27.5 \pm$ $0.5^{\circ} \mathrm{C}, 65 \% \pm 5 \%$ relative humidity $(\mathrm{RH})$ and $16: 8 \mathrm{~L}: \mathrm{D}$ photoperiod. We placed adult parasitoids into $55.5-\mathrm{mL}$ plastic vials ( $3.2 \mathrm{~cm}$ diameter by $8.3 \mathrm{~cm}$ high) containing 30 P. interpunctella last instar larvae so that they would be experienced in host searching and egg laying before they were used in experiments. The vials were capped with lids that had a $12-\mathrm{mm}$ diameter hole covered by a fine screen. Fresh eggs of $H$. hebetor for use in experiments then were obtained by placing one pair of experienced $H$. hebetor adults with 30 P. interpunctella last instar larvae, and then removing the adults from the vial after $24 \mathrm{~h}$. The $P$. interpunctella larvae with $H$. hebetor eggs were reared at $17.5^{\circ} \mathrm{C}, 20.0^{\circ} \mathrm{C}$ and $27.5^{\circ} \mathrm{C}$, under each of two photoperiods $(10: 14 \mathrm{~L}: \mathrm{D}$ and $16: 8$ $\mathrm{L}: \mathrm{D})$. Adults were collected every $24 \mathrm{~h}$ at $27.5^{\circ} \mathrm{C}$ and every 3.5 days at $17.5^{\circ} \mathrm{C}$ and $20.0^{\circ} \mathrm{C}$, and then the adults were stored at $-80^{\circ} \mathrm{C}$ until needed for analyses described below.

\section{Total RNA isolation and first-strand cDNA synthesis}

Total RNA was isolated from $100 \mathrm{mg}$ of $H$. hebetor adults using TRIzol reagent (Invitrogen Life Technologies, Grand Island, NY, USA) according to the procedure described by Zhu (2009). Total RNA was treated with deoxyribonuclease (Dnase I: Fermentas Inc., Burlington, ON, Canada) to remove possible residual genomic DNA. The concentration of RNA was determined by Nanodrop (Thermo Fisher Scientific Inc, Waltham, MA, USA). One microgram of total RNA was reverse transcribed to cDNA using a first-strand cDNA synthesis kit (Fermentas) according to the manufacturer's protocol. 


\section{Generation of Hsp70 and Rps3 partial cDNAs}

Degenerate primers of $H s p 70$ s were designed according to the highly conserved amino acid sequences of known insect Hsp 70s from the honey bee, Apis mellifera (GenBank ID: NM_001160072) (Williams et al., 2008), apple maggot fly, Rhagoletis pomonella (GenBank ID: EF103584) (Rinehart et al., 2007) and the endoparasitoid, Pteromalus puparum (GenBank ID: FJ798091) (Wang et al., 2008), by using a strategy similar to that described by Mahroof et al. (2005). The amino acid sequences of the red flour beetle, Tribolium castaneum (GenBank ID: NP_001165863.1) (Lord et al., 2010), the fruit fly, Drosophila melanogaster (GenBank ID: AAF56129.1) (Adams et al., 2000), and the European corn borer, Ostrinia nubilalis (GenBank ID: AAR98922.1) (Li et al., 2005) were used to design degenerate primers for $H$. hebetor ribosomal protein $\mathrm{S} 3$ (Rps3) gene to be used as an internal reference (Table 1). Specific Hsp70 and Rps 3 fragments were amplified from cDNA by using PCR Smart Mix (Invitrogen), and PCR amplifications were hot-started at $94^{\circ} \mathrm{C}$ for $3 \mathrm{~min}$, followed by three cycles at $94^{\circ} \mathrm{C}$ for $1 \mathrm{~min}$, annealing at $40^{\circ} \mathrm{C}$ for $1 \mathrm{~min}$ and extension at $72^{\circ} \mathrm{C}$ for $2 \mathrm{~min}$. These then were followed by 35 cycles at $94^{\circ} \mathrm{C}$ for $1 \mathrm{~min}, 55^{\circ} \mathrm{C}$ for $1 \mathrm{~min}, 72^{\circ} \mathrm{C}$ for $2 \mathrm{~min}$ and a final extension at $72^{\circ} \mathrm{C}$ for $10 \mathrm{~min}$. PCR was performed using a PTC-200 thermal cycler (MJ Research, Waltham, MA, USA).

Amplified DNA fragments of predicted sizes were purified by using QIAEX II Agarose Gel Extraction kit (Qiagen, Valencia, CA, USA) and subcloned into $\mathrm{pCR}^{\circledR} 2.1$ vector (Invitrogen) according to the manufacturer's protocol. Plasmid DNA was then purified by using Zyppy ${ }^{\mathrm{TM}}$ Plasmid Miniprep kit (Zymo, Orange, CA, USA). EcoRI was used to digest the plasmid DNA, which was then subjected to gel electrophoresis to verify whether or not the target was inserted. Once the insert targets were confirmed, the nucleotide sequences of plasmid DNA that included the target fragment DNA were determined by using a 3730 DNA Analyzer (Applied Biosystems, Foster City, CA, USA). Sequences were further examined for their identities by BLASTN search (http://blast.ncbi.nlm.nih.gov/Blast.cgi).

\section{RACE}

A $3^{\prime}$ and $5^{\prime}$-full RACE kit (Takara Biotechnology Inc, Dalian, China) was used to obtain the $3^{\prime}$ and $5^{\prime}$ ends of the $H s p 70$ cDNAs. The basic strategy for $3^{\prime}$ RACE was to synthesize first strand cDNA by reverse transcription of total RNA with $3^{\prime}$ RACE adaptor primer, and then use the Hsp 70 gene-specific outer primer and 3' RACE outer primer to perform the first round PCR. The $H s p 70$ gene-specific inner primer, $3^{\prime}$ RACE inner primer, and first-round PCR product were then used to run the secondround PCR. For 5' RACE, the $5^{\prime}$ RACE adaptor was ligated to the messenger RNA (mRNA) using T4 RNA ligase, and the mRNA was then reverse transcribed to cDNA by using reverse transcriptase M-MLV (Moloney murine leukemia virus) and random 9 mers. When the cDNA was prepared, the first- and second-round PCRs were performed using outer primers and inner primers. The primers for $3^{\prime}$ RACE (Hsp70I-3O, Hsp70I-3I, Hsp70II-3O, Hsp70II-3I, Hsp70III-3O and Hsp70III-3I) and 5' RACE (Hsp70I5O, Hsp70I-5I, Hsp70II-5O, Hsp70II-5I, Hsp70III-5O and Hsp70III-5I) (Table 1) were designed and synthesized based on the partial $H s p 70$ cDNA sequences. The $3^{\prime}$ and $5^{\prime}$ RACE were performed based on the manufacturer's procedure of $3^{\prime}$ and 5'-full RACE kit. The PCR products were subjected to electrophoresis, and the expected bands were cut from the gel and purified using Zomen Agarose Gel Extraction kit (Zomen Biotechnology, Beijing, China). After the extracted DNA was subcloned into $p E A S Y$-T1 plasmid vector (Transgen Biotechnology, Beijing, China) according to the manufacturer's protocol, the plasmid vector was used to transform Escherichia coli. The inserted cDNAs were sequenced by using a 3730 DNA Analyzer (Applied Biosystems) and M13 forward and reverse primers. The sequences were then analyzed by a blast search (NCBI: http://blast.ncbi.nlm.nih.gov/Blast.cgi).

\section{Analysis of deduced amino acid sequences of $\mathrm{Hsp} 70$ cDNAs}

After the amino acid sequences were deduced from $H s p 70$ cDNA sequences, multiple sequence alignment was performed using the ExPASy Proteomics website (http://expasy.org). The neighbor-joining method in MEGA 5.05 (http://www.megasoftware.net/mega.php) was used to construct phylogenetic trees based on the Hsp70 amino acid sequences from this study and from other species of Hymenoptera. A bootstrap analysis was conducted, and each cluster was verified using 5000 replicates (Felsenstein, 1985). Other protein sequence analysis tools used in this study (molecular mass, isoelectric point and motif sequences site search) were obtained from the ExPASy Proteomics website (http://expasy.org/).

\section{$R T-q P C R$}

RT-qPCR was performed by $\mathrm{MyiQ}^{\mathrm{TM}} 2$ Two-Color Real-Time PCR Detection System (Bio-Rad, Hercules, 
Table 1 The degenerate and gene-specific primers used for cloning the partial and full-length $H s p 70$ cDNA sequences and for quantitative PCR analysis.

\begin{tabular}{|c|c|c|c|c|c|c|}
\hline $\begin{array}{l}\text { Application } \\
\text { of primers }\end{array}$ & $\begin{array}{l}\text { Gene } \\
\text { name }\end{array}$ & $\begin{array}{l}\text { Primer } \\
\text { name }\end{array}$ & Type & Nucleotide sequence $\left(5^{\prime}-3^{\prime}\right)$ & $\begin{array}{l}\text { Temp. } \\
{ }^{\circ} \mathrm{C}\end{array}$ & $\begin{array}{c}\text { PCR } \\
\text { product } \\
\text { size }(b p)\end{array}$ \\
\hline \multirow{2}{*}{$\begin{array}{l}\text { Amplification of } \\
\text { cDNA fragments }\end{array}$} & Hsp70 & Hsp70F & $\mathrm{D}$ & GGNGGNGARGAYTTYGA & & 684 \\
\hline & & Hsp70R & $\mathrm{D}$ & RTTRTTRTCYTTNGTCAT & & \\
\hline \multirow[t]{2}{*}{$\begin{array}{l}\text { Internal reference } \\
\text { gene }\end{array}$} & $\begin{array}{l}\text { Ribosomal } \\
\text { protein S3 }\end{array}$ & RPS3F & $\mathrm{D}$ & GARATHATHATHATGGC & & 327 \\
\hline & & RPS3R & $\mathrm{D}$ & GGYAGNTGYTTRAAGTA & & \\
\hline \multirow[t]{8}{*}{ 3' RACE } & Hsp70I & Hsp70I-3'O & $\mathrm{S}$ & ATTGAAACTGCTGGTGGC & 54.0 & 971 \\
\hline & Hsp $70 I I$ & Hsp70II-3'O & $\mathrm{S}$ & CGTTGCTTATGGTGCTGC & 56.0 & 713 \\
\hline & Hsp70III & Hsp70III-3'O & $\mathrm{S}$ & АCTTCTTCAACGGCAAGG & 54.0 & 1281 \\
\hline & & $\begin{array}{l}\text { 3'RACE Outer } \\
\text { Primer }\end{array}$ & & TACCGTCGTTCCACTAGTGATTT & 58.6 & \\
\hline & Hsp $70 I$ & Hsp70I-3'I & $\mathrm{S}$ & CGATAATCAGCCTGGAGT & 54.0 & 882 \\
\hline & Hsp70II & Hsp70II-3'I & $\mathrm{S}$ & CATCCAGGTGTACGAGGGC & 56.0 & 506 \\
\hline & Hsp70III & Hsp70III-3'I & $\mathrm{S}$ & TGTCTTGATCCAGGTCTACG & 60.0 & 1025 \\
\hline & & $\begin{array}{l}\text { 3'RACE Inner } \\
\text { Primer }\end{array}$ & & CGCGGATCCTCCACTAGTGATTTCACTATAGG & 66.1 & \\
\hline \multirow[t]{8}{*}{ 5' RACE } & Hsp70I & Hsp70I-5'O & $\mathrm{S}$ & CGATCTCGATGGTAGCCTCTGT & 51.0 & 956 \\
\hline & Hsp70II & Hsp70II-5'O & $\mathrm{S}$ & ATTTCAATCCTGACCTGGTGGC & 51.0 & 1105 \\
\hline & Hsp70III & Hsp70III-5'O & $\mathrm{S}$ & TCGCACGCTCACAAGCTGTCCT & 51.1 & 958 \\
\hline & & $\begin{array}{l}\text { 5'RACE Outer } \\
\text { Primer }\end{array}$ & & CATGGCTACATGCTGACAGCCTA & 61.6 & \\
\hline & Hsp70I & Hsp70I-5'I & $\mathrm{S}$ & CGCAGTCTCCTCAAAGCCCTAG & 51.1 & 894 \\
\hline & Hsp70II & Hsp70II-5'I & $\mathrm{S}$ & TCCTTTCTGATGTCCTTGCCCT & 51.0 & 1021 \\
\hline & Hsp70III & Hsp70III-5'I & $\mathrm{S}$ & CCTTCTTGTACTTGCGCTT & 56.0 & 899 \\
\hline & & $\begin{array}{l}\text { 5'RACE Inner } \\
\text { Primer }\end{array}$ & & CGCGGATCCACAGCCTACTGATGATCAGTCGATG & 70.7 & \\
\hline \multirow[t]{8}{*}{ RT-qPCR analysis } & Hsp $70 I$ & Hsp70IF & $\mathrm{S}$ & GAGAAAGTATAGAAAGGATATGA & 57.9 & 101 \\
\hline & & Hsp70IR & $\mathrm{S}$ & CCTCTGTACTAGATGACAA & 58.1 & \\
\hline & Hsp $70 I I$ & Hsp70IIF & $\mathrm{S}$ & GCTCTACAAGAAGAAGAAG & 57.8 & 197 \\
\hline & & Hsp70IIR & $\mathrm{S}$ & AATCAATGTTCAACTCCTC & 58.0 & \\
\hline & Hsp70III & Hsp70IIIF & $\mathrm{S}$ & CTCAACAAGTCCATCAAC & 58.5 & 190 \\
\hline & & Hsp70IIIR & $\mathrm{S}$ & TTGGAATGGTTGTGTTAC & 57.9 & \\
\hline & $\begin{array}{l}\text { Ribosomal } \\
\text { protein S3 }\end{array}$ & RPS3F & $\mathrm{S}$ & GACGAATTTCATGCTCTT & 58.2 & 151 \\
\hline & & RPS3R & $\mathrm{S}$ & GTCACTCAGATACAAACTC & 57.9 & \\
\hline
\end{tabular}

O, outer primer; I, inner primer; F, forward; R, reverse; D, degenerate primer; S, gene-specific primer; RACE, rapid amplification of cDNA ends; RT-qPCR, reverse transcription quantitative polymerase chain reaction.

CA, USA), and the expression of $H s p 70$ genes in each sample was tested through comparative CT method, $2^{\Delta \Delta C_{\mathrm{T}}}$ (Livak \& Schmittgen, 2001). Rps3 was chosen as the reference gene. The concentration of cDNA was adjusted by Rps 3 before RT-qPCR was performed.
Each treatment was replicated with four biological samples, and each biological sample included two technical replicates. The sequences of the Hsp 70 and Rps3 primers used for RT-qPCR analyses are shown in Table 1. 


\section{Statistical analysis}

Relative levels of $H s p 70$ transcripts in $H$. hebetor reared at different conditions were compared with that from $H$. hebetor reared at $27.5^{\circ} \mathrm{C}$ and $16: 8 \mathrm{~L}: \mathrm{D}$, which was considered as a control. For data obtained from RT-qPCR, the changes in expression of the target genes were normalized to Rps 3 first, and then the relative expression levels in percentage for each gene were calculated by dividing the relative expression value (REV) of each gene in each rearing condition by the REV of the same gene in all conditions. The REV values were transformed using the arcsine square root transformation, and the transformed data were compared using one-way analysis of variance (ANOVA) and Tukey's b test $(P=0.05)$ across the different rearing conditions using SPSS software (SPSS, Inc., 2007).

\section{Results}

\section{Sequencing and characterization of $\mathrm{Hsp} 70$ cDNAs}

By using the degenerated primers in our PCR amplification of $H s p 70 \mathrm{cDNAs}$ from $H$. hebetor, we obtained three PCR fragments with lengths of 649, 637 and 645 bp. The deduced amino acid sequences of these PCR fragments showed $94 \%-99 \%$ identities to the same regions of Hsp70s from Microplitis mediator (GenBank ID: ABN54440), P. puparum (GenBank ID: ACO57618), T. castaneum (GenBank ID: EEZ98819), Loxostege stic- ticalis (GenBank ID: ACD63049), Megachile rotundata (GenBank ID: AAS57865) and Camponotus floridanus (GenBank ID: EFN65945).

Based on the cDNA sequence of three PCR products, we performed RACE PCR and successfully obtained the full-length cDNAs of the three putative $H s p 70$ genes from $H$. hebetor. These genes were named as HhHsp70I(B4), HhHsp70II(B6) and HhHsp70III(A6) with GenBank accession numbers of JQ839279, JQ839280 and JQ839281, respectively. The cDNA lengths of HhHsp70I(B4), HhHsp70II(B6) and HhHsp70III(A6) were 2220, 2004 and $2417 \mathrm{bp}$ with open reading frames encoding 639, 616 and 649 amino acid residues, respectively (Table 2). A BLAST search in the NCBI showed that the deduced amino acid sequences of the three putative HhHsp 70 genes (Table 2) were highly similar to the known $h s p 70$ genes from other insect species.

\section{Amino acid sequence comparisons and phylogenetic analysis}

Three Hsp70 family signatures, signature 1 (consensus sequences: [IV]-D-L-G-T-[ST]-x-[SC]), signature 2 (consensus sequences: [LIVMF]-[LIVMFY]-[DN][LIVMFS]-G-[GSH]-[GS]-[AST]-x(3)-[ST]-[LIVM][LIVMFC]) and signature 3 (consensus sequences: [LIVMY]-x-[LIVMF]-x-G-G-x-[ST]-\{LS $\}$-[LIVM]-P$x$-[LIVM]-x-[DEQKRSTA]) were found in our deduced HhHsp70 amino acid sequences by PROSITE analysis

Table 2 Nucleotide and putative amino acid sequences of $H h H s p 70$ genes after $3^{\prime}$ and $5^{\prime}$ RACE.

\begin{tabular}{|c|c|c|c|}
\hline & HhHsp $70 I$ & HhHsp $70 I I$ & HhHsp70III \\
\hline Full-length cDNA (bp) & 2220 & 2004 & 2417 \\
\hline $5^{\prime}$ UTR (bp) & 75 & 142 & 111 \\
\hline 3'UTR (bp) & 228 & 14 & 359 \\
\hline $\begin{array}{l}\text { Canonical polyadenylation signal sequence } \\
\text { (AATAAA) }\end{array}$ & No & No & Yes \\
\hline Poly (A) tail & Yes & Yes & Yes \\
\hline Open reading frame (ORF) (bp) & 1917 & 1848 & 1947 \\
\hline Polypeptide comprised & 639 & 616 & 649 \\
\hline Predicted molecular mass (kDa) & 73.57 & 68.05 & 73.72 \\
\hline Theoretical isoelectric point $(\mathrm{pI})$ & 5.09 & 5.24 & 4.84 \\
\hline Locations of three Hsp 70 signatures site ${ }^{\dagger}$ & $6-13,194-207,332-345$ & $35-42,223-236,360-373$ & $9-16,197-210,335-348$ \\
\hline Locations of ATP/GTP-binding motif site & $128-135$ & $158-165$ & $131-138$ \\
\hline $\begin{array}{l}\text { Locations of non-organellar consensus } \\
\text { motif site }\end{array}$ & 297-303 & $325-331$ & 300-306 \\
\hline
\end{tabular}

${ }^{\dagger}$ The locations represent the regions of the deduced amino acid sequences as presented in Fig. 1. RACE, rapid amplification of cDNA ends; UTR, untranslated region. 


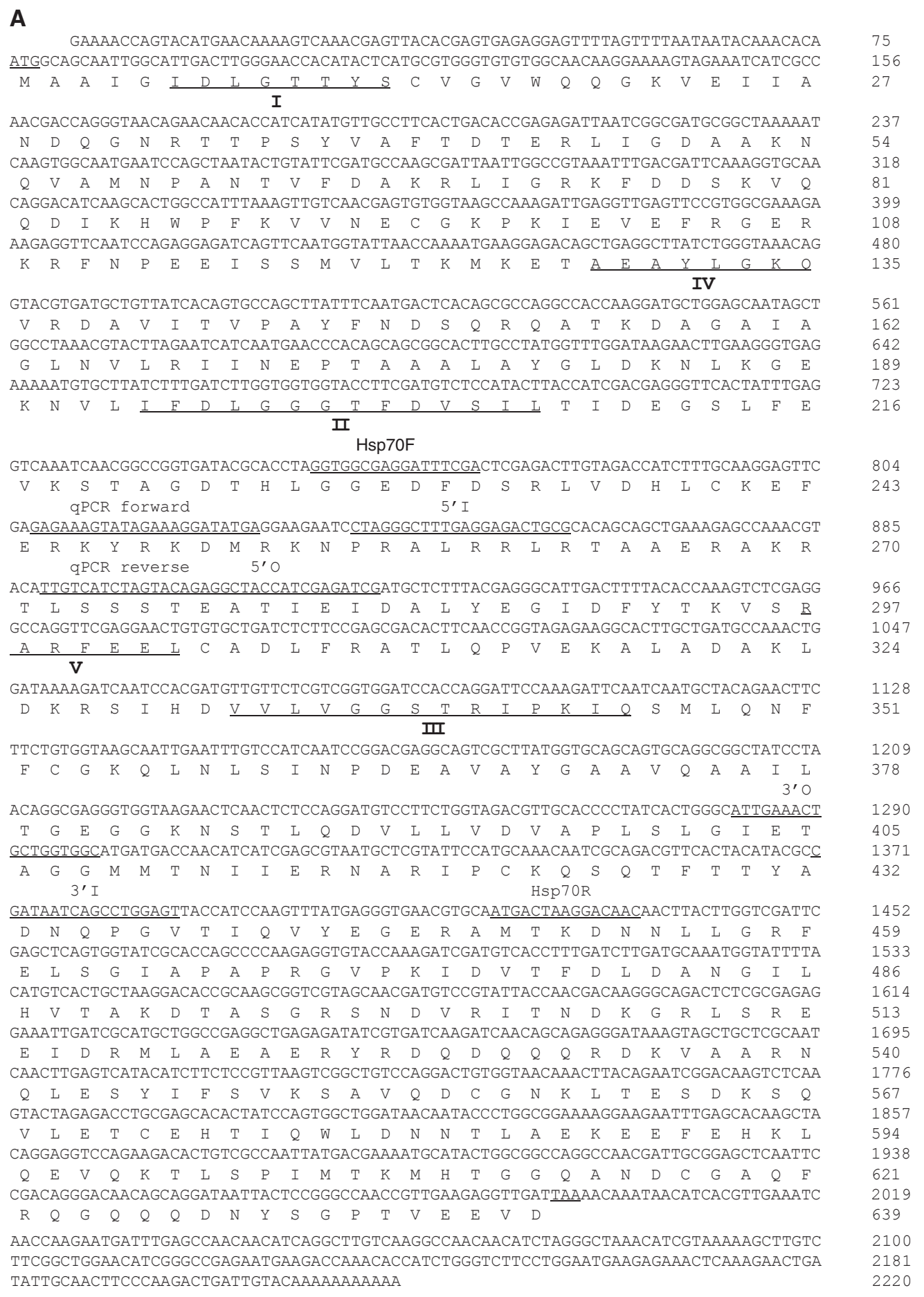

Fig. 1 Full-length cDNA sequences and deduced amino acid sequences of (A) HhHsp 70I, (B) HhHsp70II, and (C) HhHsp70III from H. hebetor. Start codons (ATG), stop codons (TAA) and the putative polyadenylation signals (AATAAA) in $H h H s p 70 I I I$ are underlined. Three signature $H s p 70$ sequences are underlined and labeled I, II, and III, and ATP-GTP binding site motif and non-organellar consensus motif are underlined and labeled as IV and V, respectively. The forward and reverse degenerate primers in $H s p 70 s$, primers for RACE and primers for RT-qPCR are underlined and labeled. 


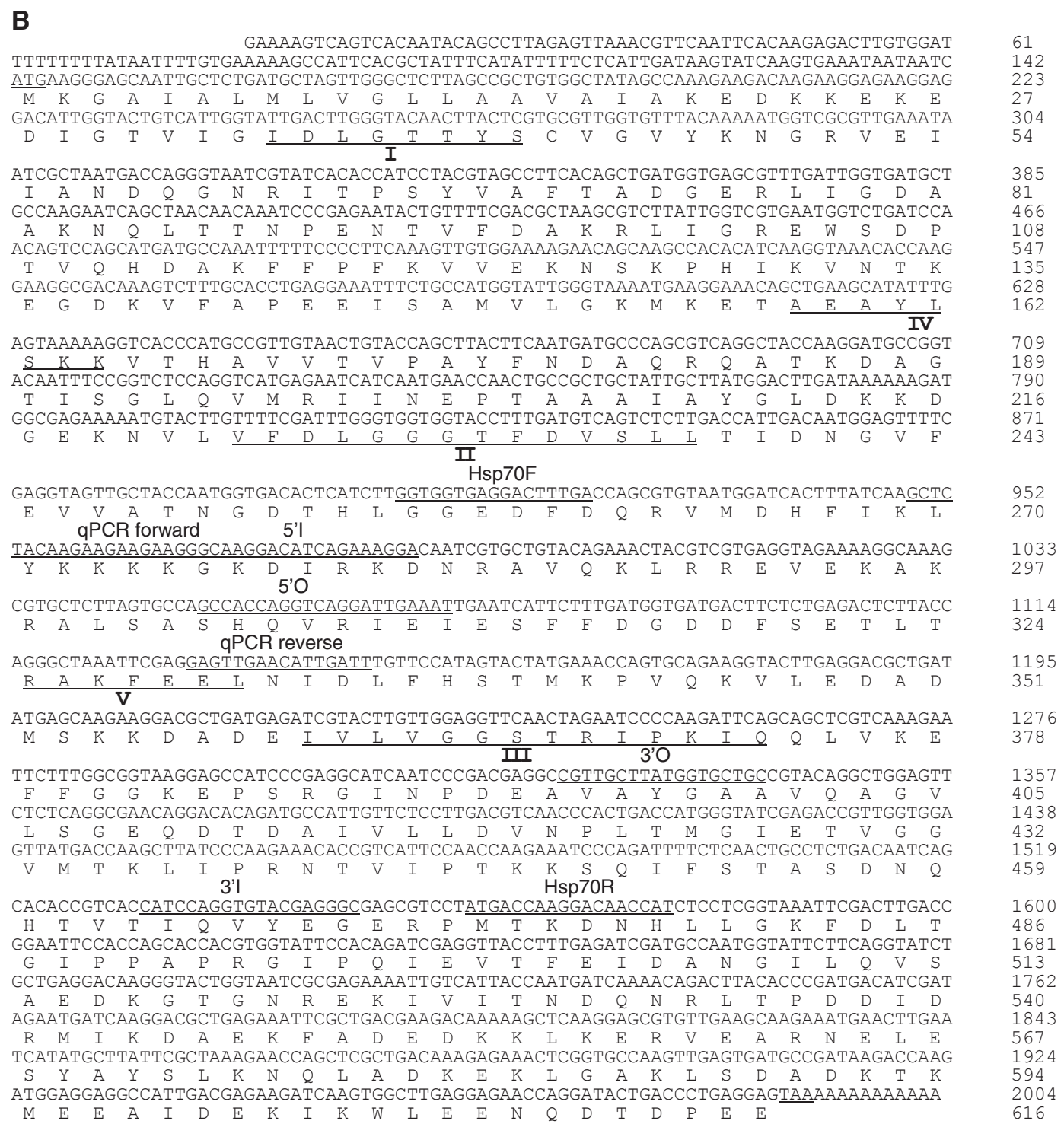

Fig. 1 Continued.

(www.expasy.org/prosite) (Fig. 1, Table 2). A notable feature in the protein is the presence of three consecutive repeats of the tetrapeptide motif GGMP in its C-terminal region for HhHsp70III.

ATP/GTP-binding site motif (Sonoda et al., 2006) and non-organellar consensus motif (Tungjitwitayakul et al., 2008) were also observed (Fig. 1, Table 2). Multiple sequence alignments showed very high homologies among the three deduced amino acid sequences of HhHsp70s and Hsp70s in other insect species. HhHsp70I was $85 \%$ identical to Macrocentrus cingulum Hsp70 (GenBank ID: ACD84944) and P. puparum Hsp70 (GenBank ID: ACO57618), and $83 \%$ identical to Nasonia vitripennis
Hsp70 (GenBank ID: XP_001604951); HhHsp70II was $84 \%$ identical to $N$. vitripennis Hsp70 (GenBank ID: XP_001606463) and C. floridanus Hsp70 (GenBank ID: EFN61604) and 83\% identical to Acromyrmex echinatior Hsp70 (GenBank ID: EGI70210); and HhHsp70III was $88 \%$ identical to P. puparum Hsp70 (GenBank ID: ACA53150) and N. vitripennis Hsp70 (GenBank ID: NP_001166228) and 87\% identical to C. floridanus Hsp70 (GenBank ID: EFN65945). However, the identity among the HhHsp70s was relatively low. Multiple sequence alignments of the $\mathrm{HhHsp} 70$ s reported in this article showed the identity was as low as $46 \%$ : HhHsp70II was $53 \%$ identical both to HhHsp70I and HhHsp70III, 


\section{C}

GAAAACTCACGTTGCGAATCGTTGAACGAG AAACAACTCGCGCCAAAGTATTAAGTATTACCCGTCCGCGTTTAATAAATTAACTAAGAAAACTAAACAAAATCAGCCAAA ATGTCTAAAGCACCTGCAGTTGGTATTGATCTTGGAACAACCTACTCCTGTGTAGGAGTTTTCCAACACGGAAAAGTTGAA $\begin{array}{llllllllllllllllllllllllllll}M & S & K & A & P & A & V & G & I & D & L & G & T & T & Y & S & C & V & G & V & F & Q & H & G & K & V & E\end{array}$ I

ATCATCGCTAATGACCAAGGAAACAGAACTACACCTAGTTATGTTGCCTTCACCGACACGGAGCGTCTCATTGGTGATGCT $\begin{array}{lllllllllllllllllllllllllllll}I & I & A & N & D & Q & G & N & R & T & T & P & S & Y & V & A & F & T & D & T & E & R & L & I & G & D & A\end{array}$

GCCAAAAACCAGGTCGCCATGAACCCCAACAACACTATTTTCGATGCCAAGAGACTGATCGGTCGTCGTTTCGATGACGCA $\begin{array}{llllllllllllllllllllllllllllll}A & K & N & O & V & A & M & N & P & N & N & T & I & F & D & A & K & R & L & I & G & R & R & F & D & D & A\end{array}$ ACTGTACAGGCTGACATGAAGCACTGGCCATTCACTGTAATCAGCGACGGTGGTAAACCAAAAATCCAAGTACAGTACAAA $\begin{array}{lllllllllllllllllllllllllllll}T & V & Q & A & D & M & K & H & W & P & F & T & V & I & S & D & G & G & K & P & K & I & Q & V & Q & Y & K\end{array}$ GGTGAAAACAAGACCTTCTACCCAGAGGAAGTAAGCTCAATGGTGCTCGTCAAAATGAAGGAGACTGCTGAGGCTTATCTT $\begin{array}{lllllllllllllllllllllllllllll}G & E & N & K & T & F & Y & P & E & E & V & S & S & M & V & L & V & K & M & K & E & T & \underline{A} & E & A & Y & L\end{array}$

GGACAAACAGTAAGCAACGCTGTTATTACTGTACCAGCGTACTTCAACGACTCGCAGCGTCAGGCAACGAAGGACGCTGGA $\begin{array}{lllllllllllllllllllllllllllll}G & Q & T & V & S & N & A & V & I & T & V & P & A & Y & F & N & D & S & Q & R & Q & A & T & K & D & A & G\end{array}$ ACCATCTCAGGCCTCAACGTGTTGCGTATCATCAACGAGCCAACCGCTGCTGCCATCGCCTACGGTCTTGACAAGAAGGCC $\begin{array}{lllllllllllllllllllllllllllll}T & I & S & G & L & N & V & L & R & I & I & N & E & P & T & A & A & A & I & A & Y & G & L & D & K & K & A\end{array}$ GTTGGTGAACGCAACGTCCTCATCTTCGATTTGGGCGGTGGTACCTTCGATGTGTCCATCCTGACAATTGAGGATGGTATC $\begin{array}{llllllllllllllllllllllllllll}V & G & E & R & N & V & L & I & F & D & L & G & G & G & T & F & D & V & S & I & L & T & I & E & D & G & I\end{array}$ 픈

TTCGAGGTCAAGTCAACCGCCGGTGACACTCACTTGGGTGGAGAGGACTTCGACAACCGCATGGTCAACCACTTTGTGCAG $\begin{array}{llllllllllllllllllllllllllll}F & E & V & K & S & T & A & G & D & T & H & \text { L } & G & G & E & D & F & D & N & R & M & V & N & H & F & V & Q\end{array}$ $5^{\prime}$ 5 'O GAGTTCAAGCGCAAGTACAAGAAGGAAAGCTCACCACCAACAAGCGTGCCCTCCGTCGTCTCAGGACAGCTTGTGAGCGTG $\begin{array}{llllllllllllllllllllllllllllll}E & F & K & R & K & Y & K & K & E & S & S & P & P & T & S & V & P & S & V & V & S & G & Q & L & V & S & V\end{array}$ CGAAGAGAACCCTCTCTTCATCCACCCCAGGCTAGCATTGAGATCGACTCTCTCTTCGAGGGTATTGACTTCTACACCTCC $\begin{array}{lllllllllllllllllllllllllllll}R & R & E & P & S & L & H & P & P & Q & A & S & I & E & I & D & S & L & F & E & G & I & D & F & Y & T & S\end{array}$ ATCACCCGTGCCCGTTTCGAGGAGCTCTGCGCTGACCTCTTCCGTGGTACCTTGGAGCCCGTTGAGAAGTCTCTCCGTGAC

$\begin{array}{lllllllllllllllllllllllllll}I & T & \frac{R}{R} & A & R & F & E & E & L & C & A & D & L & F & R & G & T & L & E & P & V & E & K & S & L & R & D\end{array}$

GCCAAGATGGACAAGGCCCAGATCCACGACATCGTCCTCGTCGGTGGCTCCACCCGTATCCCCAAGATCCAGAAGCTCCTC $\begin{array}{lllllllllllllllllllllllllllll}A & K & M & D & K & A & Q & I & H & D & I & V & L & V & G & G & S & T & R & I & P & K & I & \varrho & K & L & L\end{array}$ 3'O qPCR forward

CAGGACTTCTTCAACGGCAAGGAGCTCAACAAGTCCATCAACCCTGATGAGGCTGTCGCTTATGGTGCCGCTGTCCAAGCC $\begin{array}{lllllllllllllllllllllllllllllll}Q & D & F & F & N & G & K & E & L & N & K & S & I & N & P & D & E & A & V & A & Y & G & A & A & V & Q & A\end{array}$ GCCATTCTACACGGTGACAAGAGCGAGGCTGTCCAGGACTTGCTCCTCCTCGACGTCACCCCACTCTCGCTCGGTATTGAA

$\begin{array}{llllllllllllllllllllllllllll}A & I & L & H & G & D & K & S & E & A & V & Q & D & L & L & L & L & D & V & T & P & L & S & L & G & I & E\end{array}$ qPCR reverse

ACCGCTGGCGGTGTCATGACTGCTCTCATCAAGCGTAACACAACCATTCCAACCAAGCAGACTCAGACCTTCACCACCTAC $\begin{array}{lllllllllllllllllllllllllllll} & \text { A } & G & G & V & M & T & A & L & I & K & R & N & T & T & I & P & T & K & \& & T & \& & T & F & T & T & Y\end{array}$ $3^{\prime} \mid$ Hsp70R

GCTGACAACCAGCCCGGTGTCTTGATCCAGGTCTACGAGGGTGAGCGTGCCATGACCAAGGACAACAACCTCCTCGGAAAA $\begin{array}{llllllllllllllllllllllllllllllllll}A & D & N & Q & P & G & V & L & I & Q & V & Y & E & G & E & R & A & M & T & K & D & N & N & L & L & G & K\end{array}$ TTCGAGCTCTCTGGAATTCCACCAGCACCACGTGGTGTTCCCCAGATTGAAGTCACCTTCGACATTGATGCCAACGGTATC $\begin{array}{llllllllllllllllllllllllllllll}F & E & L & S & G & I & P & P & A & P & R & G & V & P & Q & I & E & V & T & F & D & I & D & A & N & G & I\end{array}$ CTCAACGTCTCCGCTGTCGACAAGTCGACTGGCAAGGAGAACAAGATCACCATCACCAACGACAAGGGCCGTCTGAGCAAG $\begin{array}{lllllllllllllllllllllllllllll}L & N & V & S & A & V & D & K & S & T & G & K & E & N & K & I & T & I & T & N & D & K & G & R & L & S & K\end{array}$ GAAGATATTGAGCGCATGGTCAATGAGGCCGAGAAGTACAGGAGCGAGGATGAGAAACAGAAAGAGACCATCTCTGCCAAG $\begin{array}{lllllllllllllllllllllllllllll}E & D & I & E & R & M & V & N & E & A & E & K & Y & R & S & E & D & E & K & Q & K & E & T & I & S & A & K\end{array}$ AACGGTCTCGAGTCCTACTGCTTCAACATGAAGAGCACTGTTGAAGATGAGAAACTCAAGGACAAGATCTCAGCCAGCGAC $\begin{array}{lllllllllllllllllllllllllllllll}N & G & L & E & S & Y & C & F & N & M & K & S & T & V & E & D & E & K & L & K & D & K & I & S & A & S & D\end{array}$ AAGCAGGTTGTTCTCGACAAGTGCAACGAGATCATCAAATGGCTCGATGCCAACCAGCTCGCCGACAAGGAAGAGTACGAG $\begin{array}{llllllllllllllllllllllllllllll}K & \& & V & V & L & D & K & C & N & E & I & I & K & W & L & D & A & N & Q & L & A & D & K & E & E & Y & E\end{array}$ CACAAACAGAAGGAACTCGAGGGCATCTGCAACCCAATTGTCACCAAATTGTACGCTGGTGGTATGCCCGGAGGTATGCCA $\begin{array}{lllllllllllllllllllllllllllll}H & K & Q & K & E & L & E & G & I & C & N & P & I & V & T & K & L & Y & A & G & G & M & P & G & G & M & P\end{array}$ GGCGGTGGTATGCCAGGCGCTGGCGGTGCCGCTCCAGGCGGTGCCCCCGGTGGCGGCTCCGGACCAACCATCGAGGAGGTC

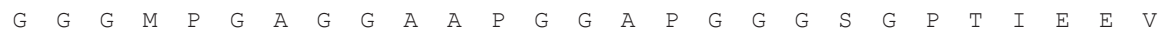
GACTAAATACCATCCTCAAAGACGAGTCATCTCCTTTATTCATCTCACATCCTCGCACCAACTTTCCAGACAATTCGTCAA $\mathrm{D}$

TGAAAAGATGACATTGAAAAATCAAGATATAGGAACACAAACGGAATTCGCTTTGCTTGACGCTACGATAATAACTTCACA TGGAAACAAATTAAACAAAAACACACCACCGTCTCTCATAAATTGACAAAAACAAAAATACTTAAATTAAAACTATTTATT GTGAAAGCATTTCATTGAGCAACTACTCCGTAGTTAGGAACATACGATCAAATGTGATGTGATTTTCCTTTTTCTATGTAE ATAAAGCGTTTTTCTGTTCCCAATCTAAAAAAAAAAAA

Fig. 1 Continued. 


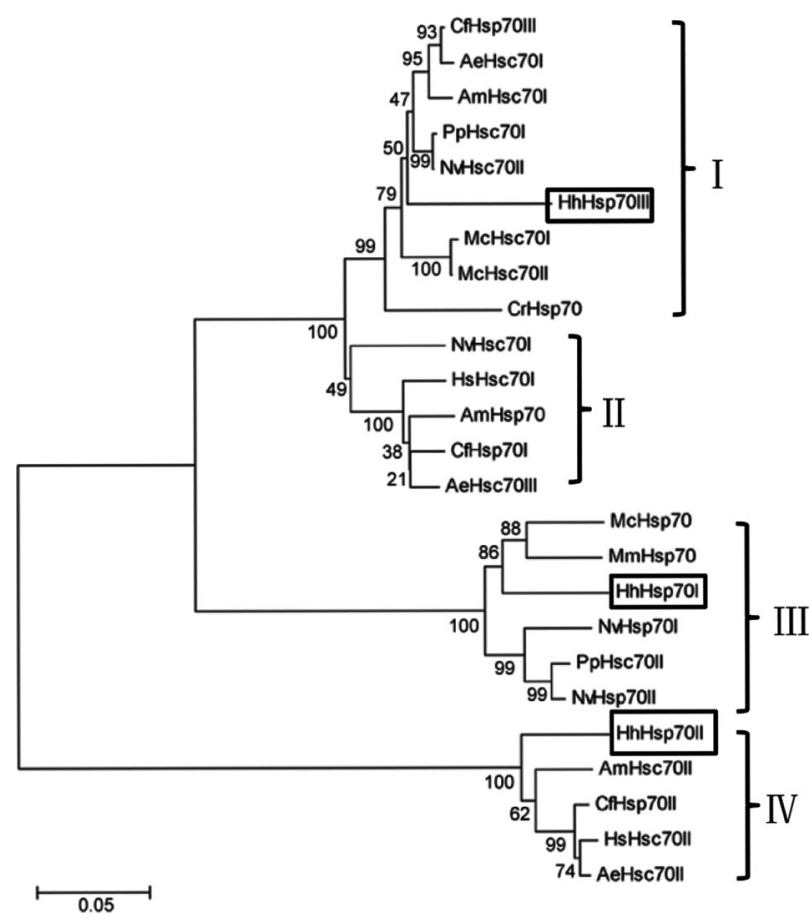

Fig. 2 A phylogenetic tree of three Hsp70s from Habrobracon hebetor and heat shock protein 70 and heat shock cognate 70 family members from other hymenopteran species constructed with the neighbor-joining method. Numbers at each branch indicate the percentage of times a node was supported in 5000 bootstrap pseudoreplications by neighbor joining.

and HhHsp70I was 66\% identical to HhHsp70III. Based on the three deduced amino acids sequences of HhHsp70 and all other known Hsp70 sequences in Hymenoptera, a phylogenetic tree was constructed using the program MEGA 5. Results show that the Hsp70s in Hymenoptera clustered into four groups, and the three HhHsp70s were distributed into three different groups (i.e., I, III and IV, Fig. 2).

Transcriptional responses of $\mathrm{Hsp} 70$ genes in $\mathrm{H}$. hebetor reared under different conditions

HhHsp 70I showed a higher transcript level when $H$. hebetor were reared at $27.5^{\circ} \mathrm{C}$ than at low temperatures $\left(17.5^{\circ} \mathrm{C}\right.$ and $\left.20^{\circ} \mathrm{C}\right)$ regardless of the photoperiod (Fig. 3). The highest transcript level for HhHsp $70 I$ was found when $H$. hebetor were reared at $27.5^{\circ} \mathrm{C}$ and $10: 14$ $\mathrm{L}: \mathrm{D}$. For $H h H s p 70 I I$, the transcript level was higher when $H$. hebetor were reared at $20^{\circ} \mathrm{C}$ and $10: 14 \mathrm{~L}: \mathrm{D}$ than when reared at $17.5^{\circ} \mathrm{C}$ and either $16: 8 \mathrm{~L}: \mathrm{D}$ or $10: 14 \mathrm{~L}: \mathrm{D}$. However, there were no significant differences among all the conditions at the two higher temperatures $\left(27.5^{\circ} \mathrm{C}\right.$ and $20^{\circ} \mathrm{C}$ ). In contrast, the transcript level of $H h H s p 70 I I I$ was stable across all rearing temperatures and photoperiods examined in this study.

\section{Discussion}

We sequenced and characterized the full-length cDNAs of three putative $H s p 70$ genes (HhHsp70I, HhHsp70II and HhHsp 70III) from $H$. hebetor. The lengths of these cDNAs, the open reading frames and the predicted molecular masses of their deduced amino acid sequences were similar to those of other known Hsp70s. All the important characteristics, including three Hsp70 family signatures and an ATP-GTP binding site in each of their deduced amino acid sequences, strongly suggest that these three genes belong to the Hsp70 family. This notion is further supported by the presence of another conserved motif (EEVD) in HhHsp70I and HhHsp70III as the members of the Hsp70 family.

Generally, members of the Hsp70 family are highly conserved, and our results underscore this high homology. However, it should be noted that their C-terminal regions are often highly divergent. The variation in sequences of the C-terminus may determine the functional specificity of individual HSPs (Demand et al., 1998; Fuertes et al., 2004; Park et al., 2007). For example, a conserved EEVD motif at the C-terminus of HhHsp70I and HhHsp70III might allow them to bind other co-chaperones (Daugarrd et al., 2007). Furthermore, some Hsp70s have GGMP repeats at the C-terminal, whereas other Hsp70 family members lack such structural elements (Boorstein et al., 1994; Boutet et al., 2003a, 2003b; Kourtidis et al., 2006). In our study, only HhHsp70III was found to possess three repeats of the tetrapeptide GGMP.

All eukaryotes investigated have more than one $H s p 70$ gene, with eight $H s p 70$ homologues documented for yeast and at least eight unique gene products for humans (Werner-Washburne \& Craig, 1989; Daugarrd et al., 2007). Phylogenetic analysis using the Hsp70 deduced amino acid sequences has been applied to many insect species (Sim et al., 2007; Wang et al., 2008; Garbuz et al., 2011). We used the neighbor-joining method to conduct a phylogenetic analysis of $21 \mathrm{Hsp} 70$ s from Hymenoptera for which full-length amino acid sequences have been identified. The three Hsp70s from H. hebetor were grouped with other Hsp70s and clustered into three different groups (Fig. 2). Such clustering patterns are also consistent with those of $A$. mellifera and $C$. floridanus (Fig. 2). Thus, these $H s p 70$ genes appear to be paralogous with each other in that they may have independently evolved from their ancestors. 


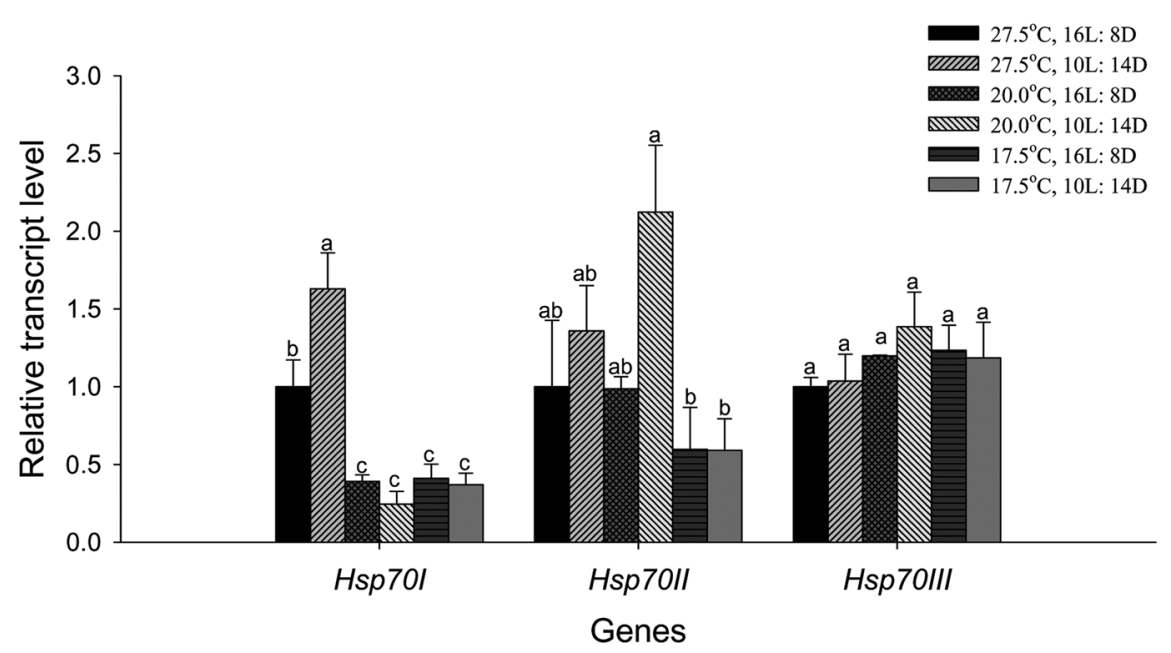

Fig. 3 Relative expression of Hsp70-like genes to Rps3 in Habrobracon hebetor reared at different conditions. Bars denoted by the same letter indicate that there are no significant differences in gene expression among the different rearing conditions (Tukey's $b \quad P>$ $0.05)$.

The expression of $H s p 70$ genes is commonly upregulated when an insect enters diapause (Rinehart et al., 2007). For example, expression of $H s p 70$ s is upregulated throughout the adult diapausing stage of the Colorado potato beetle, L. decemlineata (Yocum, 2001), and in the pupal diapausing stage of the solitary bee, M. rotundata (Yocum et al., 2005), the cotton bollworm, $H$. armigera (Bao \& Xu, 2011), the flesh fly, S. crassipalpis (Rinehart et al., 2000) and the onion maggot, Delia antiqua (Chen et al., 2006). In contrast, Hsp70 is not upregulated in the adult diapausing stage of Drosophila triauraria (Goto et al., 1998) and the house mosquito, Culex pipiens (Rinehart et al., 2006), or in the larval dipausing stage of the green bottle fly, Lucilia sericata (Tachibana et al., 2005) and the Asiatic rice borer, Chilo suppressalis (Sonoda et al., 2006). Such varied expression responses of $H s p 70$ genes in different developmental stages of diapausing insects suggest insect-specific traits related to $H s p 70 \mathrm{~s}$.

The expression of $H s p 70$ s may also be influenced by different environmental conditions. In our study, expression of three $H s p 70$ genes in $H$. hebetor reared at different conditions was quite different. Chen et al. (2012) showed that reproductive diapause can be induced at a short photoperiod at $20^{\circ} \mathrm{C}$, but not at a long photoperiod. However, in this study the expression of $H h H s p 70 I$ was found not to be different when the insect was reared at different photoperiods at $20^{\circ} \mathrm{C}$. However, the expression of HhHsp $70 I$ in $H$. hebetor reared at $27.5^{\circ} \mathrm{C}$ was higher than that when $H$. hebetor was reared at $17.5^{\circ} \mathrm{C}$ and $20^{\circ} \mathrm{C}$, regardless of the photoperiod. This implies that temperature has a greater influence on expression of HhHsp70I than the insect's diapause status. For HhHsp 70II, the transcript level was higher when $H$. hebetor were reared at $20^{\circ} \mathrm{C}$ and $10: 14 \mathrm{~L}: \mathrm{D}$ than when reared at $17.5^{\circ} \mathrm{C}$ and either $16: 18 \mathrm{~L}: \mathrm{D}$ or $10: 14$ L : D. We also found (Chen et al., 2013) that H. hebetor perform best after long-term cold storage when the wasp was reared at $20^{\circ} \mathrm{C}$ and a 10 -h photophase. Further study should be conducted on the relationship between this gene and cold tolerance in $H$. hebetor. In contrast, the expression of $H h H s p 70 I I I$ was influenced neither by the temperatures nor by the photoperiods examined in this study.

The expression of HSP genes involved in diapause may change during the course of diapause. For example, the expressions of $H s p 23$ and $H s p 70$ in $S$. crassipalpis are turned on at the onset of pupal diapause, and continue until the pupae receive a signal to resume development (Rinehart et al., 2007). On the other hand, the expression of Hsp90 in Helicoverpa zea is not consistent during pupal diapause; it is downregulated after the first 3 days, stays at a low expression level for about 1 month, and then increases when the pupae enter deep diapause (Zhang \& Denlinger, 2010). Also, Hsp70s may not be consistently involved in diapause. For example, one $H s p 70$ is upregulated during adult diapause of $L$. decemlineata, but another $H_{s p} 70$ is unchanged during diapause (Yocum, 2001). In addition, the expression of $H s p$ genes may be upregulated in the pre-adult stage in species with adult (reproductive) diapause (Rinehart et al., 2007). Thus, unlike the upregulation of $H s p$ genes in some of other diapausing insects, 
the Hsp70s in $H$. hebetor are not simply upregulated during diapause. Our results suggest that the upregulation of Hsp 70s is not universal among diapausing insects and that there may be functional differences among the three $H h$ Hsp 70 genes in H. hebetor.

\section{Acknowledgments}

The authors thank Judy Johnson (USDA-ARS, Parlier, CA) for providing Habrobracon hebetor used in the study, Rizana Mahroof for her helpful comments on an earlier draft of this manuscript, and Ann Redmon, Xin Zhang, Jianxiu Yao, Yanhui Lu and Guanghui Tang for their technical assistance. This research was supported by the China National Science and Technology Project of the 11 th FiveYear Plan (2006BAI09B04-06 and 2006BAD02A18-03), the Earmarked Fund for Modern Agro-industry Technology Research System of China (CARS-27) to H.Y. Zhang, and a scholarship from the China Scholarship Council to H.L. Chen. Mention of trade names or commercial products in this publication is solely for the purpose of providing specific information and does not imply recommendation or endorsement by the US Department of Agriculture or Kansas State University. USDA is an equal opportunity provider and employer. This is contribution no. 13-027-J from the Kansas Agricultural Experiment Station, Kansas State University.

\section{Disclosure}

This manuscript and its authors are not involved in any potential conflicts of interest, including financial interests and relationships and affiliations.

\section{References}

Adams, M.D., Celniker, S.E., Holt, R.A., Evans, C.A., Gocayne, J.D., Amanatides, P.G., Scherer, S.E., Li, P.W., Hoskins, R.A., Galle, R.F., George, R.A., Lewis, S.E., Richards, S., Ashburner, M., Henderson, S.N., Sutton, G.G., Wortman, J.R., Yandell, M.D., Zhang, Q., Chen, L.X., Brandon, R.C., Rogers, Y.H., Blazej, R.G., Champe, M., Pfeiffer, B.D., Wan, K.H., Doyle, C., Baxter, E.G., Helt, G., Nelson, C.R., Gabor, G.L., Abril, J.F., Agbayani, A., An, H.J., Andrews-Pfannkoch, C., Baldwin, D., Ballew, R.M., Basu, A., Baxendale, J., Bayraktaroglu, L., Beasley, E.M., Beeson, K.Y., Benos, P.V., Berman, B.P., Bhandari, D., Bolshakov, S., Borkova, D., Botchan, M.R., Bouck, J., Brokstein, P., Brottier, P., Burtis, K.C., Busam, D.A., Butler, H., Cadieu, E., Center, A., Chandra, I., Cherry, J.M., Cawley, S., Dahlke, C., Davenport, L.B., Davies, P., de
Pablos, B., Delcher, A., Deng, Z., Mays, A.D., Dew, I., Dietz, S.M., Dodson, K., Doup, L.E., Downes, M., Dugan-Rocha, S., Dunkov, B.C., Dunn, P., Durbin, K.J., Evangelista, C.C., Ferraz, C., Ferriera, S., Fleischmann, W., Fosler, C., Gabrielian, A.E., Garg, N.S., Gelbart, W.M., Glasser, K., Glodek, A., Gong, F., Gorrell, J.H., Gu, Z., Guan, P., Harris, M., Harris, N.L., Harvey, D., Heiman, T.J., Hernandez, J.R., Houck, J., Hostin, D., Houston, K.A., Howland, T.J., Wei, M.H., Ibegwam, C., Jalali, M., Kalush, F., Karpen, G.H., Ke, Z., Kennison, J.A., Ketchum, K.A., Kimmel, B.E., Kodira, C.D., Kraft, C., Kravitz, S., Kulp, D., Lai, Z., Lasko, P., Lei, Y., Levitsky, A.A., Li, J., Li, Z., Liang, Y., Lin, X., Liu, X., Mattei, B., McIntosh, T.C., McLeod, M.P., McPherson, D., Merkulov, G., Milshina, N.V., Mobarry, C., Morris, J., Moshrefi, A., Mount, S.M., Moy, M., Murphy, B., Murphy, L., Muzny, D.M., Nelson, D.L., Nelson, D.R., Nelson, K.A., Nixon, K., Nusskern, D.R., Pacleb, J.M., Palazzolo, M., Pittman, G.S., Pan, S., Pollard, J., Puri, V., Reese, M.G., Reinert, K., Remington, K., Saunders, R.D., Scheeler, F., Shen, H., Shue, B.C., Sidén-Kiamos, I., Simpson, M., Skupski, M.P., Smith, T., Spier, E., Spradling, A.C., Stapleton, M., Strong, R., Sun, E., Svirskas, R., Tector, C., Turner, R., Venter, E., Wang, A.H., Wang, X., Wang, Z.Y., Wassarman, D.A., Weinstock, G.M., Weissenbach, J., Williams, S.M., Woodage, T., Worley, K.C., Wu, D., Yang, S., Yao, Q.A., Ye, J., Yeh, R.F., Zaveri, J.S., Zhan, M., Zhang, G., Zhao, Q., Zheng, L., Zheng, X.H., Zhong, F.N., Zhong, W., Zhou, X., Zhu, S., Zhu, X., Smith, H.O., Gibbs, R.A., Myers, E.W., Rubin, G.M. and Venter, J.C. (2000) The genome sequence of Drosophila melanogaster. Science, 287, 2185-2195.

Amir-Maafi, M. and Chi, H. (2006) Demography of Habrobracon hebetor (Hymenoptera: Braconidae) on two pyralid hosts (Lepidoptera: Pyralidae). Annals of the Entomological Society of America, 99, 84-90.

Aruda, A.M., Baumgartner, M.F., Reitzel, A.M. and Tarrant, A.M. (2011) Heat shock protein expression during stress and diapause in the marine copepod Calanus finmarchicus. Journal of Insect Physiology, 57, 665-675.

Balevski, N. (1984) Use of the parasite Habrobracon hebetor Say for biological control. Rastitelna Zashchita, 3, 28-29.

Bao, B. and $\mathrm{Xu}, \mathrm{W}$. (2011) Identification of gene expression changes associated with the initiation of diapause in the brain of the cotton bollworm, Helicoverpa armigera. BMC Genomics, 12, 224.

Boorstein, W.R., Ziegelhoffer, T. and Craig, E.A. (1994) Molecular evolution of the HSP70 multigene family. Journal of Molecular Evolution, 38, 1-17.

Boutet, I., Tanguy, A. and Moraga, D. (2003a) Organization and nucleotide sequence of the European flat oyster Ostrea edulis heat shock cognate 70 ( hsc70) and heat shock protein 70 (hsp 70) genes. Aquatic Toxicology, 65, 221-225. 
Boutet, I., Tanguy, A., Rousseau, S., Auffret, M. and Moraga, D. (2003b) Molecular identification and expression of heat shock cognate $70(h s c 70)$ and heat shock protein (hsp 70) genes in the pacific oyster Crassostrea gigas. Cell Stress \& Chaperones, 8, 76-85.

Brower, J.H. and Press, J.W. (1990) Interaction of Bracon hebetor (Hymenoptera: Braconidae) and Trichogramma pretiosum (Hymenoptera: Trichogrammatidae) in suppressing storedproduct populations in small inshell peanut storages. Journal of Economic Entomology, 83, 1096-1101.

Chapman, R.F. (1998) The Insects: Structure and Function. 4th edn. Cambridge University Press, Cambridge. 954 pp.

Chen, B., Kayukawa, T., Monteiro, A. and Ishikawa, Y. (2006) Cloning and characterization of the HSP70 gene, and its expression in response to diapauses and thermal stress in the onion maggot, Delia antiqua. Journal of Biochemistry and Molecular Biology, 39, 749-758.

Chen, H.L., Zhang, H.Y., Zhu, K.Y. and Throne, J.E. (2012) Induction of reproductive diapause in Habrobracon hebetor (Hymenoptera: Braconidae) when reared at different photoperiods at low temperatures. Environmental Entomology, 41, 697-705.

Chen, H.L., Zhang, H.Y., Zhu, K.Y. and Throne, J.E. (2013) Performance of diapausing parasitoid wasps, Habrobracon hebetor, after cold storage. Biological Control, 64, 186-194.

Cheng, W.Y. (1991) Importation of natural enemies for the control of sugarcane insect pests in Taiwan in 1955 to 1989. Taiwan Sugar, 38, 11-17.

Cline, D.L. and Press, J.W. (1990) Reduction in almond moth (Lepidoptera: Pyralidae) infestations using commercial packaging of foods in combination with the parasitic wasp, Bracon hebetor (Hymenoptera: Braconidae). Journal of Economic Entomology, 83, 1110-1113.

Danks, H.V. (1987) Insect Dormancy: An Ecological Perspective. Biological Survey of Canada, Ottawa $439 \mathrm{pp}$.

Daugarrd, M., Rohde, M. and Jäättelä, M. (2007) The heat shock protein 70 family: highly homologous proteins with overlapping and distinct functions. FEBS Letters, 581, 37023710 .

Demand, J., Lüders, J. and Höhfeld, J. (1998) The carboxyterminal domain of Hsc70 provides binding sites for a distinct set of chaperone cofactors. Molecular and Cellular Biology, 18, 2023-2038.

Denlinger, D.L. (1991) Relationship between cold hardiness and diapause. Insects at Low Temperature (eds. R.E. Lee \& D.L. Denlinger), pp. 174-198. Chapman and Hall Press, New York.

Denlinger, D.L. (2008) Why study diapause? Entomological Research, 38, 1-9.

Feder, M.E. and Hoffman, G.E. (1999) Heat-shock proteins, molecular chaperones, and the stress response: Evolutionary and ecological physiology. Annual Review of Physiology, 61, 243-282.
Felsenstein, J. (1985) Confidence limits on phylogenies: An approach using the bootstrap. Evolution, 39, 783-791.

Foerster, L.A. and Doetzer, A.K. (2006) Cold storage of the egg parasitoids Trissolcus basalis (Wollaston) and Telenomus podisi Ashmead (Hymenoptera: Scelionidae). Biological Control, 36, 232-237.

Fuertes, M.A., Pérez, J.M., Soto, M., Menéndez, M. and Alonso, C. (2004) Thermodynamic stability of the C-terminal domain of the human inducible heat shock protein 70. Biochimica et Biophysica Acta, 1699, 45-56.

Garba, M. and Gaoh, N.B. (2008) Use of Habrobracon hebetor in biological control of Heliocheilus albipunctella pearl millet head miner, pp. 436-444. AFPP - 8éme Conference Internationale sur les Ravageurs en Agriculture, October 22-23, 2008, Montpellier SupAgro, France.

Garbuz, D.G., Yushenova, I.A., Zatsepina, O.G., Przhiboro, A.A., Bettencourt, B.R. and Evgen'ev, M.B. (2011) Organization and evolution of hsp70 clusters strikingly differ in two species of Stratiomyidae (Diptera) inhabiting thermally contrasting environments. BMC Evolutionary Biology, 11, 74.

Gerling, D. (1971) Occurrence, abundance, and efficiency of some local parasitoids attacking Spodoptera littoralis (Lepidoptera: Noctuidae) in selected cotton fields in Israel. Annals of the Entomological Society of America, 64, 492-499.

Goto, S.G., Yoshida, K.M. and Kimura, M.T. (1998) Accumulation of $H s p 70$ mRNA under environmental stresses in diapausing and nondiapausing adults of Drosophila triauraria. Journal of Insect Physiology, 44, 1009-1015.

Huang, X.F. (1986) Use of Habrobracon hebetor Say in granary pest control. Chinese Journal of Biological Control, 2, 78-80.

Imam, M., Uwais, A., Namat, U., Akbar, A. and Ahmat, T. (2007) Influence of Habrobracon hebetor on Helicoverpa armigera in southern Xinjiang. Natural Enemies of Insects, 29, 12-15.

Keever, D.W., Mullen, M.A., Press, J.W. and Arbogast, R.T. (1986) Augmentation of natural enemies for suppressing two major insect pests in stored farmers stock peanuts. Environmental Entomology, 15, 767-777.

Kourtidis, A., Drosopoulou, E., Nikolaidis, N., Hatzi, V.I., Chintiroglou, C.C. and Scouras, Z.G. (2006) Identification of several cytoplasmic HSP70 genes from the Mediterranean mussel (Mytilus galloprovincialis) and their long-term evolution in mollusca and metazoa. Journal of Molecular Evolution, 62, 446-459.

Kroeker, E.M. and Walker, V.K. (1991) Developmental expression and hormonal regulation of a desiccation stress protein in Tenebrio molitor. Insect Biochemistry, 21, 631640.

Lee, R.E. (1991) Principles of insect low temperature tolerance. Insects at Low Temperature (eds. R.E. Lee \& D.L. Denlinger), pp. 17-46. Chapman and Hall, New York.

Li, H., Oppert, B., Higgins, R.A., Huang, F., Buschman, L.L., Gao, J.R. and Zhu, K.Y. (2005) Characterization of cDNAs 
encoding three trypsin-like proteinases and mRNA quantitative analysis in Bt-resistant and -susceptible strains of $O s$ trinia nubilalis. Insect Biochemistry and Molecular Biology, 35, 847-860.

Livak, K.J. and Schmittgen, T.D. (2001) Analysis of relative gene expression data using real-time quantitative PCR and the $2^{\Delta \Delta C_{\mathrm{T}}}$ method. Methods, 25, 402-408.

Lord, J.C., Hartzer, K., Toutges, M. and Oppert, B. (2010) Evaluation of quantitative PCR reference genes for gene expression studies in Tribolium castaneum after fungal challenge. Journal Microbiological Methods, 80, 219-221.

Mahroof, R., Zhu, K. Y., Neven, L., Subramanyam, B. and Bai, J. (2005) Expression patterns of three heat shock protein 70 genes among developmental stages of the red flour beetle, Tribolium castaneum (Herbst) (Coleoptera: Tenebrionidae). Comparative Biochemistry and Physiology, Part A, 141, 247256.

Michaud, M.R. (2007) Molecular physiology of insect low temperature stress responses. Ph.D. dissertation. The Ohio State University, Columbus, Ohio.

Park, H., Ahn, I.Y. and Lee, H.E. (2007) Expression of heat shock protein 70 in the thermally stressed Antarctic clam Laternula elliptica. Cell Stress and Chaperones, 12, 275-282.

Press, J.W., Cline, L.D. and Flaherty, B.R. (1982) A comparison of two parasitoids, Bracon hebetor (Hymenoptera: Braconidae) and Venturia canescens (Hymenoptera: Ichneumonidae), and a predator Xylocoris flavipes (Hemiptera: Anthocoridae) in suppressing residual populations of the almond moth, Ephestia cautella (Lepidoptera: Pyralidae). Journal of Kansas Entomological Society, 55, 125-128.

Pullin, A.S. (1996) Physiological relationships between insect diapause and cold tolerance: Co-evolution or coincidence. European Journal of Entomology, 93, 121-129.

Rinehart, J.P., Robich, R.M. and Denlinger, D.L. (2006) Enhanced cold and desiccation tolerance in diapausing adults of Culex pipiens, and a role for hsp70 in response to cold shock but not as a component of the diapause program. Journal of Medical Entomology, 43, 713-722.

Rinehart, J.P., Yocum, G.D. and Denlinger, D.L. (2000) Developmental upregulation of inducible hsp70 transcripts, but not the cognate form, during pupal diapause in the flesh fly, Sarcophaga crassipalpis. Insect Biochemistry and Molecular Biology, 30, 515-521.

Rinehart, J.P., Li, A., Yocum, G.D., Robich, R.M., Hayward, S.A.L. and Denlinger, D.L. (2007) Up-regulation of heat shock proteins is essential for cold survival during insect diapause. Proceedings of the National Academy of Sciences of the United States of America, 104, 11130-11137.

Sim, C., Hong, Y.S., Tsetsarkin, K.A., Vanlandingham, D.L., Higgs, S. and Collins, F.H. (2007) Anopheles gambiae heat shock protein cognate 70B impedes o'nyong-nyong virus replication. BMC Genomics, 8, 23.
Sonoda, S., Fukumoto, K., Izumi, Y., Yoshida, H. and Tsumuki, H. (2006) Cloning of heat shock protein genes (hsp90 and hsc70) and their expression during larval diapause and cold tolerance acquisition in the rice stem borer, Chilo suppressalis Walker. Archives of Insect Biochemistry and Physiology, 63, 36-47.

SPSS, Inc. (2007) Statistical Package for Social Sciences. SPSS, Inc., Chicago, IL.

Storey, K.B. and Storey, J.M. (1991) Biochemistry of cryoprotectants. Insects at Low Temperature (eds. R.E. Lee \& D.L. Denlinger), pp. 64-93. Chapman and Hall, London.

Tachibana, S., Numata, H. and Goto, S.G. (2005) Gene expression of heat-shock proteins (Hsp23, Hsp70 and Hsp90) during and after larval diapause in the blow fly Lucilia sericata. Journal of Insect Physiology, 51, 641-647.

Tauber M.J., Tauber, C.A. and Masaki, S. (1986) Seasonal Adaptations of Insects. Oxford University Press, Oxford. 426 pp.

Tungjitwitayakul, J., Tatun, N., Singtripop, T. and Sakurai, S. (2008) Characteristic expression of three heat shockresponsive genes during larval diapause in the bamboo borer Omphisa fuscidentalis. Zoological Science, 25, 321-333.

Uwais, A., Xu, J.J., Yang, X.R., He, J., Tursun, A., Guo, W.C., Xu, Y.Q. and Wei, Y.Q. (2006) Preliminary test of controlling Helicoverpa armigera and Ostrinia furnacalis with Habrobracon hebetor in fields. Chinese Journal of Biological Control, 22, 155-157.

Wada, H., Gombos, Z. and Murata, N. (1990) Enhancement of chilling tolerance of a cyanobacterium by genetic manipulation of fatty acid desaturation. Nature, 347, 200-203.

Wang, H., Dong, S.Z., Li, K., Hu, C. and Ye, G.Y. (2008) A heat shock cognate 70 gene in the endoparasitoid, Pteromalus puparum, and its expression in relation to thermal stress. $B M B$ Reports, 41, 388-393.

Werner-Washburne, M. and Craig, E.A. (1989) Expression of members of the Saccharomyces cerevisiae hsp70 multigene family. Genome, 31, 684-689.

Williams, J.B., Roberts, S.P. and Elekonich, M.M. (2008) Age and natural metabolically-intensive behavior affect oxidative stress and antioxidant mechanisms. Experimental Gerontology, 43, 538-549.

Yocum, G.D. (2001) Differential expression of two HSP70 transcripts in response to cold shock, thermoperiod, and adult diapause in the Colorado potato beetle. Journal of Insect Physiology, 47, 1139-1145.

Yocum, G.D., Joplin, K.H. and Denlinger, D.L. (1998) Upregulation of a $23 \mathrm{kDa}$ small heat shock protein transcript during pupal diapause in the flesh fly, Sarcophaga crassipalpis. Insect Biochemistry and Molecular Biology, 28, 677-682.

Yocum, G.D., Kemp, W.P., Bosch, J. and Knoblett, J.N. (2005) Temporal variation in overwintering gene expression and respiration in the solitary bee Megachile rotundata. Journal of Insect Physiology, 51, 621-629. 
Zhang, Q. and Denlinger, D.L. (2010) Molecular characterization of heat shock protein 90,70 and 70 cognate cDNAs and their expression patterns during thermal stress and pupal diapause in the corn earworm. Journal of Insect Physiology, 56, $138-150$.
Zhu, K.Y. (2009) Isolation of nucleic acids from insects. Handbook of Nucleic Acid Purification (ed. D. Liu), pp. 297-315. CRC Press, Boca Raton, FL.

Accepted March 21, 2013 